\title{
LICOFRÓN: DE NUEVO SOBRE 'INTERPOLACIONES ROMANAS', FECHA, GÉNERO Y REPRESENTACIÓN
}

\author{
PABLO A. CAVALLERO \\ UBA-UCA-CONICET. Argentina
}

Resumen: Acerca de Alejandra, se insiste en la autoría de Licofrón a comienzos del s. III a.C. y se niegan las 'interpolaciones' de 1226 ss. y 1435 ss., sosteniendo que allí se alude a Alejandro Magno en homenaje a los Ptolomeos, sin necesidad de llevar la fecha de composición al s. II o a la época augustal. Asimismo, se defiende la obra como una tragedia 'helenística', sin cánones clásicos, representable en ámbito cortesano o académico y antecedente de formas bizantinas.

Palabras-clave: Licofrón - Alejandra - tragedia - helenismo

\section{LYCOPHRON: AGAIN ABOUT 'ROMAN INTERPOLATIONS', DATE, GENDER AND REPRESENTATIÓN}

\begin{abstract}
Concerning Alexandra, we propose the authorship of Lycophron at the beginning of s. III B.C. and we also refuse the 'interpolations' in $1226 \mathrm{ff}$. and $1435 \mathrm{ff}$., holding the view that they refer to Alexander the Great in honor of the Ptolemies, without having to date the composition of the poem to s. II or to the Augustan era. Also it is defended that the work is a 'Hellenistic' tragedy without classical canons, that it can be performed in courtly or academic areas and that it is a precedent of Byzantine forms.
\end{abstract}

Key-words: Lycophron - Alexandra - tragedy - Hellenism

Recibido: 2.11.15 - Aceptado: 5.01.16

Correspondencia: Pablo A. Cavallero

Email: pcavalle@filo.uba.ar pablo.a.cavallero@gmail.com

Doctor en Letras. Profesor titular regular de Lengua y cultura griegas. Investigador en el Consejo Nacional de Investigaciones Científicas. Director de la Sección Filología Medieval del Instituto de Filología Clásica (Facultad de Filosofía y Letras, Universidad de Buenos Aires). Miembro de número de la Academia Argentina de Letras. Instituciones:

Universidad de Buenos Aires - CONICET - Universidad Católica Argentina

Dirección particular: Helguera 4445, C 1419 Buenos Aires. 
T a obra se conserva en una decena de códices más fragmentos papiráceos ${ }^{1}$. Según la Suda ( $\lambda$ 827), su autor es un erudito tragediógrafo contemporáneo de Ptolomeo Filadelfo, rey entre 285 y 246 a.C.; Aristófanes de Bizancio (c. 257-c. 180 a.C.) ya lo cita a comienzos del s. II a.C. ${ }^{2}$. Pero esta ubicación temporal es cuestionada por algunos críticos, debido a que en los versos 1225-1280 y 1446-1450 aparecería Roma como ya triunfante, lo cual llevaría la fecha de composición a un siglo después, por lo menos. Un escolio al v. 1226 señala, en una versión, que el autor sería otro Licofrón ${ }^{3}$; en 1827, Niebuhr apoyó esa propuesta; en 1880 Fox opinó que o se trata de otro Licofrón o esos pasajes son una interpolación. Momigliano llamó la atención sobre que no se conoce otro poeta con tal nombre y que la expresión de dominio en "tierra y mar" (vv. 1229, 1245, 1448) es una fórmula helenística que no implica el imperio romano ${ }^{4}$. Koerte-Händel no ven una solución convincente. Scheer atetizó el pasaje en su edición, indicando una laguna tras el v. 1280 y adelantando los versos 1214-1225 como siguientes al v. 1173. Tarn ${ }^{5}$ opina que la obra tiene que tener una fecha posterior. Perret ${ }^{6}$ señala que la fuente de los vv. 1226-1280 es Fabio Píctor (segunda mitad del s. III a.C.), no Timeo de Tauromenio (c. 350-260 a.C.), y que por lo tanto el poema debe de datar del 196 a.C., unos sesenta años después de la muerte de Licofrón de Cálcide. Para Mascialiano, Alejandra hace una apoteosis disimulada de Roma como nueva Troya, tratada lateralmente; sería la intuición de un ascenso político de Roma ${ }^{7}$. Para West, en cambio, esos loci son interpolaciones de la época augustal, quizás del mismo Teón, que gustaba del alejandrinismo y estudió la obra, aprovechando

1 Sobre la tradición textual, cf. SCHEER (1879). En cuanto a la aportación de los papiros, cf. Hartmann (1929), Criscuolo (1970), Livrea (1989) y Spatafora (1995). Hay dos fragmentos papiráceos, que Mascialino no tuvo en cuenta en su edición, pero sí Fusillo-Hurst-Paduano en la suya (Licofrone, Alessandra, Milano, 1991). Véase la actualización y estudio profundo de los papiros en MARANDINO (2010).

2 Corssen (1913: 334) insiste en la importancia de esta cita y del hecho de que el erudito haya conocido a un solo Licofrón.

3 Cf. Ceccarelli-Steinrück (1995). La hipótesis de un segundo Licofrón ha sido retomada recientemente por LAMBIN (2005), pero "el otro" sería del mismo s. III.

4 Momigliano (1928: 250); Momigliano (1942: 57).

5 TARN (1927: 241).

6 Perret (1942: 346-366, 477, 502, 505).

7 Mascialino (1956: xxxiv). 
a hacer un 'vaticinio' de la grandeza de Roma .

Como se ve, la discusión es intensa y está favorecida por la oscuridad del estilo, propia de una 'profecía' de Casandra y de una erudición alejandrina que gusta de las alusiones raras'.

Vamos a comentar el segundo fragmento en el que se considera que aparece Roma triunfante, con su contexto previo $^{10}$ :

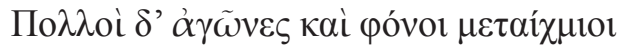

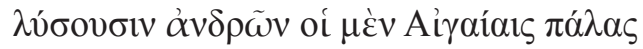

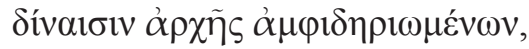

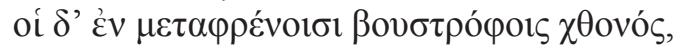

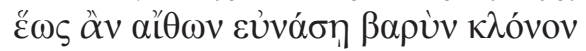

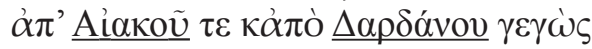

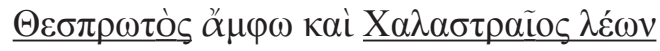

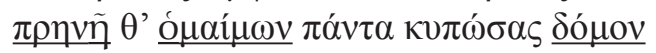

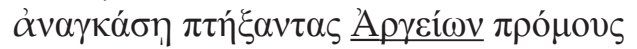

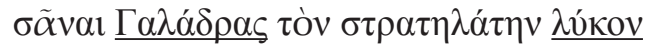

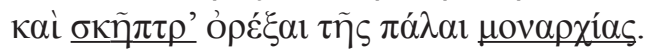

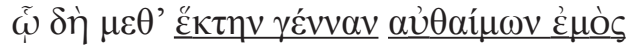

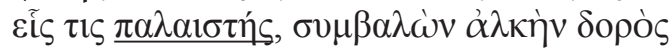

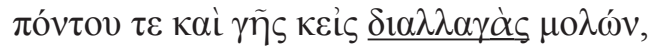

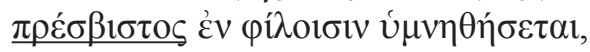

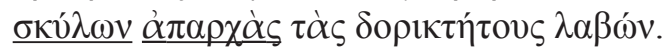

8 Cf. West (1983: 129).

9 Cf. Giangrande (1967).

10 Transcribimos de la edición de Mascialino (1964). 
La traducción es más o menos así:

Muchos combates y asesinatos en los intervalos

resolverán las luchas de hombres que pelean

por el mando, unos en los torbellinos egeos ${ }^{11}$,

otros en las espaldas de la tierra trabajadas por bueyes ${ }^{12}$,

hasta que inflamándose adormezca el gravoso tumulto

uno nacido de Éaco y de Dárdano,

león tesproto y asimismo calastreo,

y, tras abajar toda la casa caduca de consanguíneos,

fuerce a los primeros de los argivos, aterrados,

a moverle la cola a Galadras, el lobo guerrero,

y a ofrecer el cetro de la antigua monarquía;

con él, ciertamente, tras la sexta generación un cierto

luchador de mi misma sangre, arrojando el vigor de la lanza

y marchando a reconciliaciones de ponto y de tierra,

será alabado entre los amigos como el más respetable

tras tomar de los despojos las primicias adquiridas por la lanza.

Una cuestión es a quién designa "el león tesproto y calastreo nacido de Éaco y Dárdano". West opina que se trata de un líder romano; Holzinger, que se refiere a Pirro, rey de Epiro y de Macedonia, primo segundo de Alejandro Magno $^{13}$, que puso en jaque a Roma y murió en 272 a.C.; los escolios, que es Alejandro Magno, cuya madre Olimpia era de Epiro (por eso "tesproto", por ser Tesprotia el sudeste de Epiro) y su padre Filipo, de Macedonia (por eso "calastreo", dado que Calastra es ciudad de Macedonia), usando sinécdoques en ambos casos. Los molosos, pueblo de Epiro, se decían descendientes de Aquileo, por lo tanto de Éaco, pues Neoptólemo, hijo de Aquileo, se radicó en

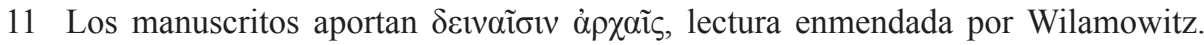
Implicaría entender "que pelean por/con tremendos mandos".

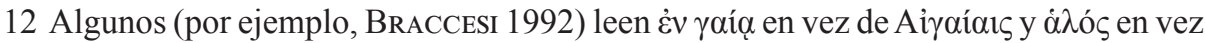
de $\chi \theta$ ovóc; la inversión hace que, de todos modos, se aluda a tierra y a mar. Obsérvese que Braccesi, seguramente por errata, omite dos hemistiquios en vv. 1440-1, pero la

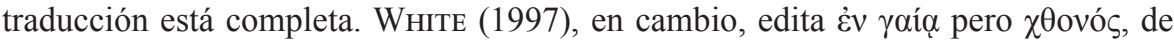
modo que ambos loci aluden a la tierra ("land" y "earth" según la traducción de Mair que White copia), interpretando que distingue tierra inculta de cultivada, aunque toda sufrirá la guerra (p. 50); defiende la lectura en White (2000: 131).

$13 \mathrm{Su}$ padre, Eácides, era primo de Olimpia, madre de Alejandro Magno. 
Epiro y Moloso, el hijo que tuvo con Andrómaca, heredó ese reino. La referencia "nacido de Dárdano" es más difícil, pues Dárdano es antepasado de los troyanos: distintas versiones del mito dicen que Héleno, hijo de Príamo y descendiente de Dárdano, casó en Epiro con Deidamía, madre de Neoptólemo, o con la misma Andrómaca ya viuda de Neoptólemo. Pero, por otra parte, como también Troya envió colonos a Tracia, región de Macedonia, su mención puede ser, pues, por metonimia, una primera referencia a este reino, que también conquistó la región llamada Dardania, al norte de los Balcanes. Así, las referencias tendrían total paralelismo: "Éaco" y "tesproto" aluden a Epiro mientras que "Dárdano" y "calastreo" a Macedonia. De tal manera, esas referencias pueden inclinarse tanto por Pirro cuanto por Alejandro Magno ${ }^{14}$.

El contexto siguiente debería desambiguar. ¿Quién redujo la casa caduca o derribada $(\pi \rho \eta v \tilde{\eta})$ de parientes (v. 1444)? Si bien era frecuente que un heredero matara a parientes que podían pretender el trono, Alejandro Magno (o su entorno) se deshizo de sus mediohermanos Carano y Europa, de su madrastra Eurídica, de su primo y ex rey Amintas IV; sobrevivió solamente su mediohermano Filipo Arrideo, a quien Alejandro creía encarnación de la diosa Gaia y quien fue su sucesor. Pirro, por su parte, tras ser expulsado por Casandro y vencido en Asia, asesinó a su co-rey Neoptólemo II de Epiro cuando éste intentaba matarlo a él (año 297); no logró mucho beneficio de su lucha contra Demetrio Poliorcetes, rey de Macedonia (294-288). La referencia, pues, parece más adecuada a Alejandro, quien triunfalmente "adormeció el gravoso tumulto" de decenios de luchas, por mar y por tierra, de helenos con persas, de helenos entre sí y de helenos con macedonios.

En los versos siguientes se dice que el tal león lograría apagar ese "gravoso tumulto" no sólo tras imponerse en su reino, sino tras forzar a otros; y que estos lo halagarían como un perro a su amo, que es presentado como "lobo de Galadras": como $\Gamma \alpha \lambda \alpha ́ \delta \rho \alpha$ es ciudad de Macedonia (cf. 1343) y el lobo es imagen tradicional de la codicia, la expresión parece referirse a Macedonia (no al monarca), que de un pequeño reino pasó a extenderse hasta el Cercano y

14 Se ha mencionado también la alusión al general romano Flaminino, que luchó contra los griegos en la primera década del s. II a.C.; SudHAus (1908: 487) señala que "wir dürfen die Alexandra bald nach der Proklamation der griechischen Freiheit bei den Isthmischen Spielen ansetzen", es decir, el año 196, y opina que "la sexta generación" no excluye el triunfo de Flaminino en Cinoscéfalas (197). Cf. West (1983: 125-6). No parece adecuado el elogio a un romano. 
Medio Oriente y hasta Egipto; el "cetro de la antigua monarquía" parece aludir a Persia ${ }^{15}$, de modo que el león ha de ser Alejandro. En cuanto a "argivos", que Scheer enmienda en A A $\tau \alpha \dot{i} \omega v$ = persas (cf. Heródoto 7: 61) pero que el escolio

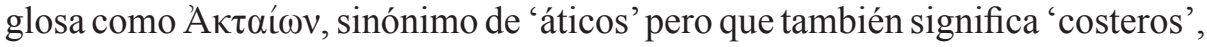
aludiría a los atenienses colonos sometidos a Persia (Mileto, Halicarnaso, etc.), de modo tal que quienes pasan a halagar al 'lobo macedonio' son tanto los atenienses cuanto los persas e incluso los griegos mercenarios al servicio de Persia, como lo estaba Memnón de Rodas. Todos ellos le ofrecen "el cetro" persa al conquistador. Pirro, por su parte, fue rey de Macedonia apenas dos años en dos períodos, mientras que reinó más de veinticinco en Epiro. Intentó extenderse a Italia, Sicilia y Cartago, pero sus triunfos acabaron en derrota (la batalla de Benevento, 275 a.C.) y, además, Roma era entonces una República, de modo que no entregó ningún cetro monárquico.

Los versos 1446 ss. también parecen inclinar la alusión a Alejandro. "Con él" o "contra él", si $\tilde{\omega}$ depende de $\sigma v \mu \beta \alpha \lambda \omega \omega v$, tiene como antecedente a $\sigma \kappa \tilde{\eta} \pi \tau \rho o v$, es decir, el cetro persa cedido a Macedonia, si es correcta la interpretación anterior ${ }^{16}$. "Tras la sexta generación" alude a las Guerras Médicas $^{17}$, acaecidas unos ciento cincuenta años antes de la conquista realizada por Alejandro (pensemos que Filipo tuvo a su primer hijo a los veintidós años y que Alejandro tuvo al suyo -Heracles- a los treinta y uno; la edad habitual de casamiento de un ciudadano griego era a los treinta años, pero la comedia suele presentar hijos extramatrimoniales de padres más jóvenes ${ }^{18}$. Si la sexta

15 Muchos entienden que es Grecia, dominada por Alejandro tras la destrucción de Tebas; cf. por ejemplo BraCCESI (1992: 507).

16 Ya Cessi (1912: 76 y 81) rechazaba que el $\pi \alpha \lambda \alpha \iota \tau \tau \dot{\varsigma}$ aludiese a un romano.

17 Fernández Galiano (1987: 146) traduce "pasados seis años" para dar coherencia a su interpretación. Para él los "argivos" son los Argéadas (cf. nota 963), dinastía de Filipo de Macedonia, vencida por Pirro, quien hizo que Alejandro, hijo de Casandro y nieto de Filipo, se sometiera a Demetrio Poliorcetes; los seis años aludirían a la guerra de Pirro en Italia (280-274) y el pariente al que se refiere la profetisa sería Gayo Fabricio Luscino, 'descendiente' de Eneas en tanto romano (cf. notas 9646), que firmó la paz con Pirro. Sigue en esto a, por ejemplo, Rollo (1928), quien concluye, atento a esa interpretación, que "non multo post a. 275 a.C.n. Alexandra tota a poeta nostro Alexandriae vel alibi composita est" (p. 101). Rollo destaca que Pirro fue el sexto rey después de Alejandro Magno. Pero hay que advertir que el texto dice "después de la sexta generación".

18 La crítica suele interpretar que el punto de partida (la 'primera' generación) era la 
generación concluye en 330 a.C., los últimos años de este rey y sus grandes logros están "después de" ella, como indica la 'profecía'. Alejandro es un "luchador" por excelencia y es $\alpha \hat{v} \theta \alpha \dot{\mu} \mu \omega v$ 'de la misma sangre' de AlejandraCasandra en tanto los molosos, antepasados maternos de Alejandro, descendían de Andrómaca, cuñada de Casandra, y de Héleno, su hermano. Alejandro arroja con su cetro y con Macedonia el vigor de su lanza tanto por tierra cuanto por mar; pero brega por reconciliaciones $(\delta 1 \alpha \lambda \lambda \alpha \gamma \dot{\alpha} \varsigma)$, primero con la Liga helénica, luego tratando de construir en Oriente un imperio cosmopolita, extendiendo la cultura griega (lengua, teatro, hipódromo, biblioteca) y promoviendo la unión

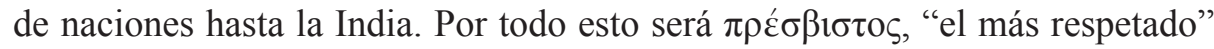

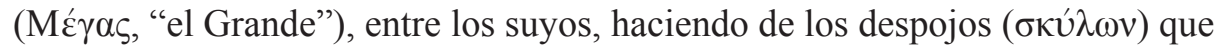
dejan los enemigos en la guerra verdaderas "primicias", ofrendas conquistadas por la lanza. Más que destruir, Alejandro busca resarcir al mundo griego de las ofensas persas de otrora ${ }^{19}$.

En fin, creemos que este discutido sector alude a Alejandro Magno. Y nos parece lógico que, si el autor es Licofrón de Cálcide y compone su obra para la corte de Ptolomeo Filadelfo, el poeta haga un elogio de Alejandro Magno, admirador y restaurador de Troya, patria de Casandra, y fundador del Imperio del que Ptolomeo era, al menos en parte, heredero. El padre de Ptolomeo II Filadelfo, Ptolomeo I Soter, había sido amigo y compañero dilecto de Alejandro ${ }^{20}$ : todo el poema es un elogio de Troya-Macedonia y de la Grecia macedónica contemporánea, homenaje indirecto a sus gobernantes ptolomeos.

En cuanto al primer pasaje discutido, vv. 1226-1280, atetizado por Scheer y considerado interpolación por West ("una segunda mano que aumenta

del tiempo de Alejandro y sus conquistas. Por ejemplo, WeSt (1984: 134). BracCESI (1992: 508) parte de la batalla de Gaugamela (331 a.C.) y considera que las seis generaciones son trescientos años, para concluir que se alude a la batalla de Accio (31 a.C.) y a Augusto pacificador. Por su parte, White (1997) opina que las seis generaciones se extienden desde la muerte de Alejandro Magno (323) hasta la batalla de Pidna (168), ciento cincuenta y cinco años, y que el guerrero aludido es Emilio Paulo, quien venció a Perseo, puso fin al reino de Macedonia y obtuvo sus despojos.

19 West (1983: 127) propuso que el $\pi \rho \varepsilon ́ \sigma \beta 1 \sigma \tau o \varsigma$ fuese Augusto. BRACCESI (1992: 5101) coincide; como el término no se repite en Licofrón, cree que es de un interpolador que suma augustus y princeps.

$20 \mathrm{Al}$ período en torno al año 270 vincula el poema A. Coppola $\mathrm{Il}$ re, il barbaro, il tiranno. Poesia e ideologia in età ellenistica, Padova, 2002, cap. 2 (non vidi; apud Prioux). 
lo itálico"21), su evaluación es quizás más complicada. Que el autor haya querido dar relieve al mundo itálico es comprensible si él es Licofrón: hijo adoptivo de Lico de Regio, vivió en Italia probablemente y, si no, la conoció y apreció a través de su padre. Es comprensible que haya recibido noticia de las leyendas que hacen de Roma heredera de Troya a través de Eneas. Tito Livio menciona la llegada de los troyanos a diversos puntos de la península itálica y Virgilio le da una impronta épicamente poética. Ambos pudieron usar datos de Quinto Fabio Píctor, historiador romano que escribía en griego, que nació aproximadamente cuando murió Licofrón y cuya obra fue traducida al latín en época de Cicerón. Se cree que utilizó crónicas de las familias patricias de Roma, pero su conocimiento del griego y su viaje a Delfos pudieron proporcionarle también otras fuentes. Más allá de lo que Fabio pudo haber recopilado y puesto por escrito, no es inverosímil que la leyenda circulara por vía oral, tanto en la Magna Grecia e Italia cuanto en la Grecia helenística, y que Licofrón la conociera a través de Lico, también éste historiador ${ }^{22}$.

Con estos presupuestos, no resulta imposible que Licofrón aludiera, pues, a Roma y a su crecimiento y expansión. En su época, Roma era ya dueña de todo el centro de la península y Pirro, precisamente, intentó que les diera independencia a varios de los pueblos anexados. Dado que Pirro fracasó, si Alejandra es posterior al 272 a.C., el poema puede reflejar esta resistencia romana que augura una mayor expansión; y si es posterior al 265 a.C., puede aludir ya a la conquista del sur itálico, es decir, la Magna Grecia. Y en 261 a.C. Roma ganaba el sur de Sicilia con el triunfo de Agrigento.

No hace falta, pues, ubicar el pasaje en el s. I a.C. para justificar la alusión al engrandecimiento de Roma: es aceptable ya en el 260 a.C. Pero veamos el locus más en detalle.

21 West (1984: 129). Para la erudita, la pieza tuvo también otras "interpolaciones" menores (cf. pp. 137 ss.). Las alteraciones textuales que encuentra West fueron denegadas por White (2000).

22 Sobre la circulación de mitos y el vínculo de representaciones pictóricas con Alejandra, cf. ahora Haumesser (2014), quien lo advierte en una tumba de Etruria. Asimismo, Prioux (2009), para quien habría "mitos locales" en diversas versiones, que Licofrón habría intentado 'conciliar'. Gigante LANZARA (1999: 342) señala que los "antiguos oráculos" mencionados a propósito de las mesas devoradas (v. 1252) pueden ser "ripresa di un mito già noto". 


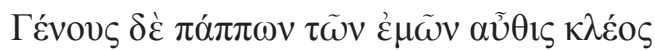

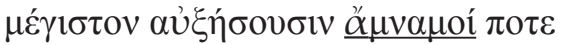

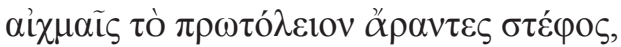

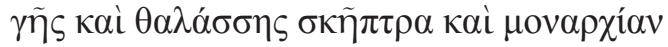

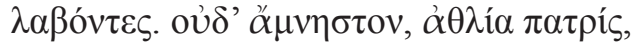

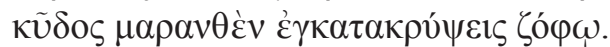

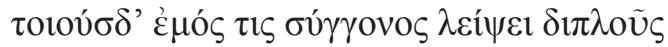

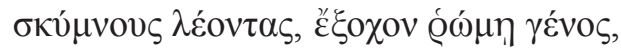

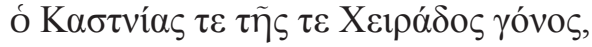

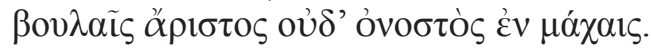

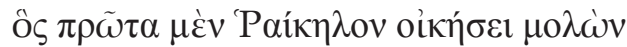

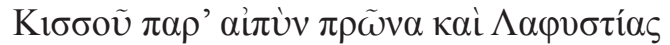

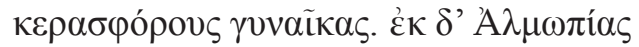

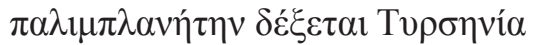

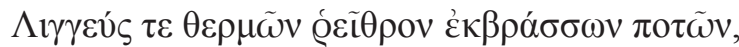

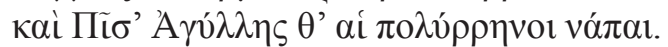

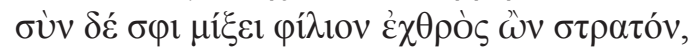

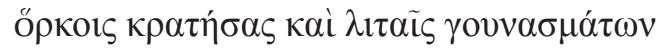

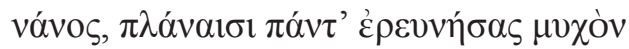

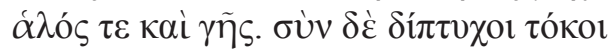

1245

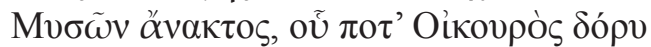

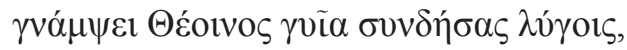

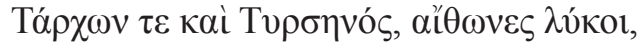

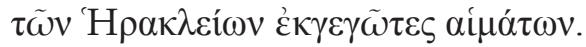

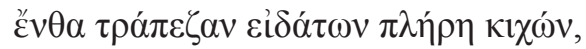

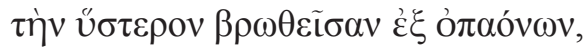

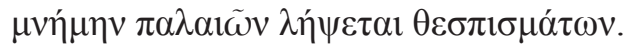

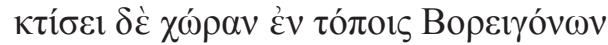

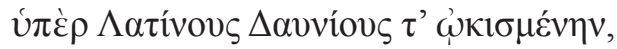

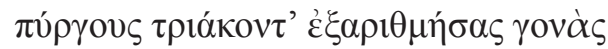

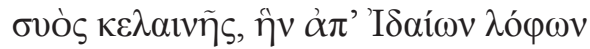

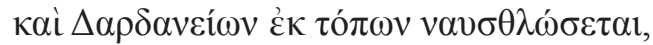

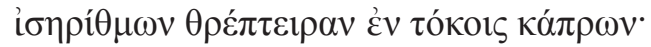

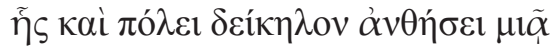

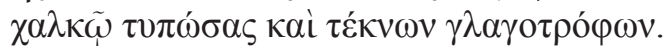

$\delta \varepsilon i ́ \mu \alpha \varsigma \delta$ غ̇ $\sigma \eta \kappa o ̀ v ~ M v v \delta i ́ \alpha$ П $\alpha \lambda \lambda \eta v i ́ \delta 1$

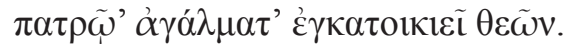

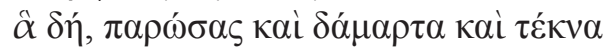




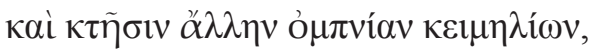

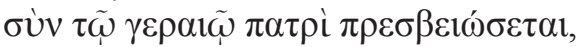

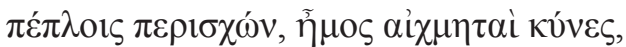

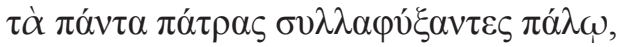

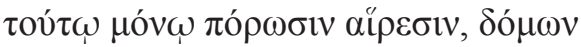

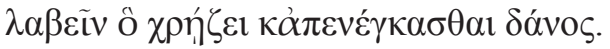

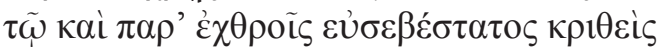

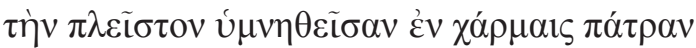

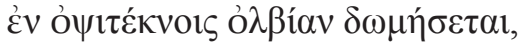

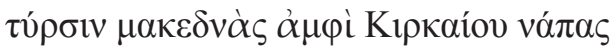

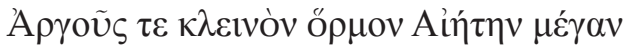

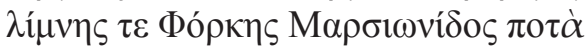

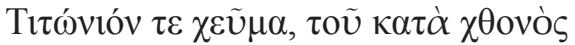

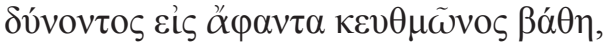

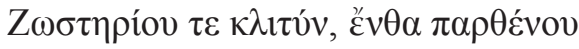

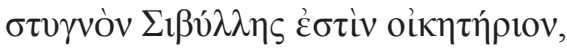

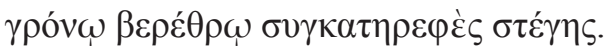

Ensayamos esta traducción:

La gloria de la estirpe de mis abuelos de nuevo acrecentarán los descendientes como la más grande, alguna vez, alzando con lanzas la corona primicia del botín tras tomar cetro y monarquía de la tierra y el mar; y no olvidable renombre, desdichada patria, ocultarás como consumido por tiniebla. Dejará cierto pariente mío dos tales leones cachorros, raza eminente en vigor, el vástago de Castnia y de la del arrecife, excelente en consejos y no desdeñable en combates, el cual primeramente habitará Recelo junto al escarpado promontorio de Ciso y a las devoradoras mujeres portadoras de cuernos; desde Almopia al nuevo errante recibirán Tirrenia y el Lingeo que arroja la corriente de cálidas aguas, y Pisa y los valles de Agila, de muchos corderos. Siendo enemigo mezclará consigo un ejército amistoso, 
tras forzarlo con juramentos y con súplicas de arrodillados, un enano, después de indagar con su vagar todo rincón del salado mar y de la tierra; y junto con él, los dos hijos del jefe de los misios, cuya espada alguna vez el guardián de la casa, dios del vino, doblegará atando los miembros con flexibles ramas, Tarcón y Tirreno, lobos ardientes nacidos de las sangres heracleas. Allí, tras encontrar una mesa llena de alimentos, devorada después por los colegas, recibirá noticia de antiguas predicciones.

Fundará en los lugares de los boreales un país habitado por latinos y daunios, treinta torres, tras enumerar las crías

de una cerda negra a la que, desde las cimas del Ida y desde los lugares dardanios embarcará, nodriza en partos de igual número de lechones.

Una figura de ella erigirá también, para la ciudad, tras modelarla en bronce, y de sus hijos nutridos con leche.

Después de edificar un templo a la mindia palénide, establecerá estatuas patrias de los dioses.

Ciertamente, tras poner de lado no sólo a la esposa sino también a los hijos

y toda fructífera adquisición de posesiones, a aquéllas [estatuas] reverenciará con el anciano padre envolviéndolas en vestidos, cuando los belicosos perros, tras devorar al sorteo todo lo de la patria, sólo a éste concedan como elección tomar de la casa y llevarse el don que solicite.

Juzgado por esto como piadosísimo, incluso por los enemigos, la patria sumamente alabada en los combates de los tardíos hijos la construirá afortunada, una fortificación en torno de los largos valles del Circeo y del gran Eetes, puerto célebre de Argo, y de las aguas del marsio lago de Force y de la corriente titonia -al sumergirse ella bajo tierra en las profundidades de una grutay de la pendiente del Sosterio, donde está la morada horrenda de la virgen Sibila, 
cubierta con el cavado agujero del techo ${ }^{23}$.

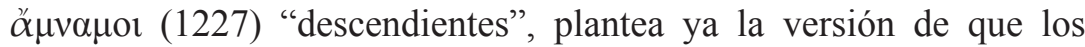
romanos (y los vénetos) descienden de los troyanos. Los vv. 1229-30 tendrán eco en los vv. 1446, 1449 y 1451, lo cual puede sugerir una cierta comparación entre Macedonia y Roma: si el reino de Macedonia construyó un Imperio, Roma, que está en plena expansión, puede emularla. La mención del mar, más allá de ser parte de un giro, puede aludir a la conquista de Sicilia, de modo que podría ser considerada como una referencia al año 260 a.C.

Continúa la alusión a la leyenda romana: los dos cachorros son Rómulo y Remo (1233) 24 ; los dejará Eneas, descendiente de Afrodita (la del monte Kastnion y la nacida entre las olas, v. 1234), que recala en Macedonia (Recelo, Ciso, Almopia). No menciona el paso de Eneas por Cartago sino que lo lleva a la Toscana (el río Lingeo o Arno, Pisa) y Etruria (Agila). Alude a Odiseo (el enano $)^{25}$, antiguo enemigo con quien hace las paces, como también con los hijos de Télefo (hijo de Heracles), Tarcón y Tirreno (v. 1245), el primero aliado de Heracles, el segundo hijo de éste, según una versión ${ }^{26}$. Se alude luego a la mesa de alimentos (los que arruinan las Hárpias, cf. Eneida 3: 219 ss. y 7: 112-115) y a las predicciones (de Celeno sobre la mesa devorada, cf. Eneida 3: 245 ss.; de Héleno, cf. Eneida 3: 369 ss.; de la Sibila, cf. Eneida 6: 42 ss.; de Anquises 7: 122-127). El país, Roma, cuya fundación menciona, incluye a Apulia (los daunios), correctamente indicada como "boreal” si el autor es de Calabria: Regio,

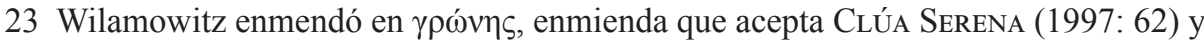
que implica entender "del cavado techo".

24 Si se adopta la variante $\lambda \varepsilon ́ o v \tau o \varsigma$ como hace Clúa SERENA (1997: 62), no se modifica el sentido final: el león sería Eneas y los "cachorros de león" siguen siendo ellos mismos leones.

25 Sobre la baja estatura de Odiseo cf. Ilíada 3: 193 y Odisea 6: 230. Podría haber varias alusiones: Tzetzes dice que en etrusco nanos significa 'vagabundo'; Dionisio de Halicarnaso menciona un rey pelasgo, Nanas, que habría colonizado Cortona; Teopompo señala que Odiseo se fue de Ítaca por la mala conducta de Penélopa y se instaló en Italia. Sobre estas posibilidades, cf. Prioux (2009).

26 Son de los pocos nombres propios mencionados, habitualmente de personajes secundarios o desconocidos (salvo vv. 798-803). Tarcón daría origen al topónimo Tarquinii y Tirreno al nombre del mar; la tradición más conocida da origen lidio a estos dos hombres. Licofrón, que reúne tradiciones, querría destacar el doble origen pelasgo y lidio-misio de los etruscos (cf. PriOux 2009). 
patria de Lico, está en el extremo sur de Italia, sobre el estrecho que la separa de Sicilia, de modo que Apulia queda al norte. Y si este país aludido abarca Apulia, incluye Samnia, que se ubica entre Apulia y el Lacio y que estaba bajo poder romano ya en 290 a.C.

También la cerda y los treinta lechones aparecen en la Eneida (3: 389-393), que recoge la misma leyenda, como predicción dicha por Héleno, hermano mellizo de Casandra. Sólo que allí la cerda es blanca ("sus.../alba"

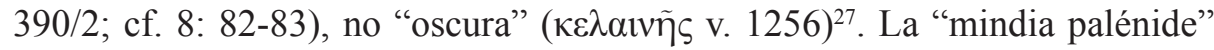
es Atena, del dêmos de Palena, a la que asocia a Myndos, ciudad de Caria, al sudoeste del Asia Menor, por alguna versión mitológica ignota.

Como es típico de las predicciones de Casandra, hay avances y retrocesos en la cronología ${ }^{28}$, cuales se dan también en Agamenón 1072 ss. de Ésquilo, donde la profetisa oscila entre los crímenes de Atreo, el que hará Clitemnestra, retrocede a Troya, vuelve a Tiestes y de nuevo a Clitemnestra. En Alejandra 1263 ss., la mención del templo y estatuas que establecerá Eneas hace que la profecía retorne al momento del saqueo de Troya en manos de los "belicosos perros" (los argivos): Eneas dejará a su familia, tomará a su padre Anquises y las estatuas penates, lo único que puede llevarse de su casa. Como apósito sintáctico de la patria que construirá, aparece una "fortaleza" (1273) que el poeta rodea de lugares cuyos nombres evocan la Cólquide (Circeo, Eetes, Argo) pero también Samnia (los marsios, el cabo Sosterio), Campania (la Sibila de Cumas) y el Lacio (cabo Circeo). La predicción parece exaltar el desorden propio del delirio profético.

Es cierto que el gusto por las profecías, en época de Teón y Virgilio (pensemos en la égloga IV, por ejemplo), pudo crear un interés especial por la obra de Licofrón; pero esto no asegura que se la haya 'retocado'. En realidad, todo lo que se incluye aquí pertenece a la leyenda antigua de Eneas y de la llegada de los troyanos a Italia; ningún detalle corresponde específicamente a la

27 De tal modo se vincula el portento con el nombre de Alba Longa; cf. Varrón De lingua latina 5: 144 "hinc post triginta annos oppidum alterum conditur, Alba; id ab sue alba nominatum"; Propercio 4: 1.35 "Alba potens, albae suis omine nata".

28 Por ejemplo, la destrucción de Troya, tratada en la primera parte del poema, reaparece brevemente en 1369 ss., y la muerte de Agamenón y Casandra, detallada en 1108 ss., vuelve brevemente en 1372 ss. 
época augustal ${ }^{29}$, sino que la expansión romana aludida bien se encuadra en la que tuvo lugar durante la primera mitad del s. III a.C., es decir, en la época de la $\dot{\alpha} \kappa \mu \eta ́$ de Licofrón de Cálcide.

Por lo tanto, no es necesario considerar estos fragmentos como espurios ni como añadidos tardíos; ni dudar tampoco de la autoría reconocida por los antiguos ${ }^{30}$. Por otra parte, el interés por lo romano debe de provenir del vínculo de Licofrón con Italia y del parentesco de la profetisa con Eneas; pero lo fundamental en su poema es destacar la figura de Alejandro, que emulaba a

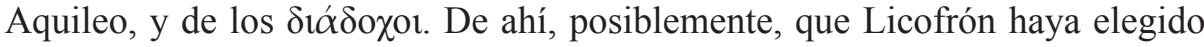
como nombre del poema 'Alejandra' y no 'Casandra': el título mismo alude ya a la exaltación pretendida.

La cuestión del género y de la posibilidad de representación

Según algunos críticos, el único nexo que el poema tiene con la tragedia es el metro. Mascialino (1956: xxxiv) rechaza que se le diga "tragoedia

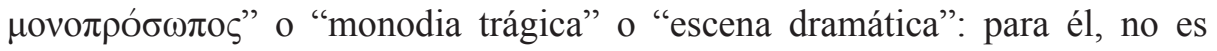
representable. Es un "poema yámbico épico-lírico"; esta obra "no permite encasillamiento alguno dentro de la literatura" ${ }^{31}$.

La Alejandra es, sin duda para nosotros, una tragedia, aun cuando se haya intentado hallar en ella elementos 'cómicos' que respondan a una teoría dramatúrgica vinculada con el Banquete de Platón: todo tragediógrafo puede ser comediógrafo ${ }^{32}$; cosa que estaría ya en cierto modo en la concepción trágica que tiene Nubes de Aristófanes ${ }^{33}$ y en su manejo teórico y práctico de

29 WeSt (1984: 133) opina que el autor tuvo que conocer la Eneida. En WeSt (1983: 132 ss.) hay un estudio de similitudes y divergencias entre este poema y Alejandra. Pensamos que el autor helenístico tuvo que conocer leyendas tradicionales que seguramente circulaban mucho antes de que Virgilio naciera.

30 Hay algún escolio que duda de que el autor sea el Licofrón del s. III; cf. WeSt (1984: 130) y particularmente CECCARELLI-STEINRÜCK (1995), quienes estudian las diferencias en las versiones de este escolio. Tzetzes califica como $\varphi \lambda v \alpha \rho i ́ \alpha$ el comentario del escolio.

31 Mascialino (1956: xxxv).

32 Cf. Hurst (1998). Hurst ha publicado una nueva edición y estudio (Paris, Les belles lettres, 2008).

33 Cf. Cavallero (2006) y Zimmermann (2006). 
la composición de tragedias, manifestado en Ranas ${ }^{34}$. Pero Alejandra es una tragedia helenística, alejandrina; no una tragedia del siglo v. Posiblemente influye, contra su valoración como una tragedia, un prejuicio anclado en el concepto clasicista ${ }^{35}$, mientras que Alejandra responde a la estética helenística:

1. retorna a las fuentes, es decir, vuelve al drama de un monologuista, al estilo anterior a Tespis, que a lo sumo incluye un diálogo en su parlamento; en el helenismo, si hay coro, es un cortejo de bailarines, no un personaje;

2. tiene gusto por una 'tradición innovadora', valga la paradoja: conserva elementos de la tradición mítico-literaria pero con matices y formatos novedosos ${ }^{36}$; mezcla leyenda, historia y visión profética y da forma dramática a la materia del ciclo épico, con lo que logra una síntesis patética; utiliza el "ricco e multiforme patrimonio linguistico del teatro" sin desdeñar el léxico de Heródoto y Xenofonte ni el científico ${ }^{37}$;

3. prefiere la obra breve; dice el texto de Alejandra "si acaso se extendiera el discurso,/ perdóname, amo" (vv. 2-3), donde se advierte la intención de brevedad. Para ser una tragedia, es relativamente breve -más si se la compara con una trilogía clásicay condice con el género dramático del mimo, cuya representación también se cuestiona;

4. tiene el gusto por la obra cincelada y erudita; no sólo esta obra es así por su lengua y sus alusiones mitológicas ${ }^{38}$, sino también

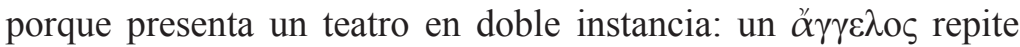
palabras de otra persona ante Príamo, un personaje-espectador;

34 Cf. Martina (1993: 92). El autor supone que también en la perdida comedia Poesía Aristófanes se ocupaba de metaliteratura.

35 Clúa Serena (2003: 50) sostiene que "No parece lógico designar como tragedia a la Alejandra, ya que le faltan rasgos esenciales"; empero, no los menciona.

36 Cf. Rossi (1971).

37 Cf. Gigante Lanzara (1997: 68). Dice Clúa Serena (1997: 57) que acepta los jonismos del texto "dada la conocida apertura de la lengua de la tragedia griega con respecto a otros dialectos". Recordemos que también el mimo de Herondas está escrito en dialecto jónico.

38 Sobre el modo de presentar los mitos, véanse como ejemplo GrIFFITHS (1986) y NAFISSI (1997). 
Estamos, pues, ante un tipo diferente de tragedia. Empero, la crítica parece juzgarla desde cánones 'clasicistas'. La Suda ( $\lambda$ 827) denomina

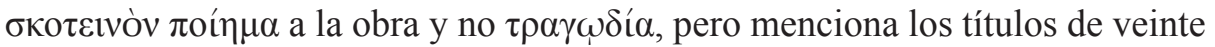
tragedias de este autor, de los que cuatro tendrían asunto histórico; Tzetzes, por su parte, al comentar el escolio al v. 1226, parece referirse a la obra como $\tau \grave{\eta} v$ $\tau \rho \alpha \gamma \omega \delta$ í $\alpha v$, aunque los códices de su obra, que citan el escolio, dicen $\tau \rho \omega \alpha ́ \delta \alpha$ u omiten el pasaje $\mathrm{e}^{39} \mathrm{y}$ él, al considerar las particularidades de la obra, parece no considerarla entre las tragedias del autor. Diógenes Laercio, Vita Menedemi II

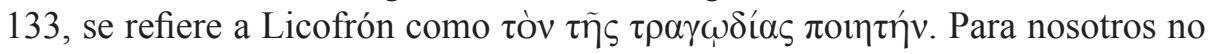
hay contradicción entre la denominación de 'poema' o de 'tragedia'.

Quizás, pues, no sea válido pretender encontrar en Alejandra ciertos

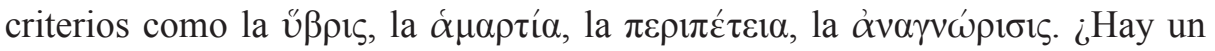
héroe trágico, una situación trágica, una caída en el infortunio? En realidad, el discurso de Casandra repetido por el Guardia-servidor-mensajero ante Príamo presenta como personajes trágicos a los griegos, que se creen felices por su triunfo pero se perderán en el vó $\tau$ os, casi todos, o morirán al regresar, como Agamenón, por la üßpıs de la violación de la misma Casandra por parte de Ayante (cf. vv. 365-6), falta que generó el rito expiatorio que duraría mil años (cf. vv. 1141 y 1153$)^{40}$; y también son trágicos los troyanos, que en la persona de Paris cometen la úßpıৎ de violar la hospitalidad de Menelao (cf. vv. 136-7) ${ }^{41}$ pero que durante la profecía se saben todavía felices poseedores de su patria y no entienden la ruina que se les anuncia, incluido entre ellos el mismo 'público' Príamo, que escucha la información sin poder comprenderla. La $\alpha \mu \alpha \rho \tau i ́ \alpha$ que los hace caer de su supuesta felicidad y seguridad es, precisamente, no entender -por lo tanto, no creer- la advertencia de Casandra, mantenerse en la ignorancia, quizás por una ă $\tau \eta$, 'ofuscamiento', inducida por Apolo. Por supuesto, la

39 La omisión sería un salteo ex homoeoteleuto. Cf. los escolios en SCHEER (1908: II XVI-XVII). CeCCARELli-STEINRÜCK (1995: 83 ss.) proponen que T $\rho \omega \alpha ́ \delta \alpha$ era la lección original del escolio y que aludía a la parte 'troyana' de Alejandra, de modo que la hipótesis de una interpolación sería muy antigua.

40 Cada año, vírgenes locrias debían ir a Troya para aplacar la ira de Atenea a causa de la violación perpetrada por Ayante. BRACCESI (1992: 507) señala que, de acuerdo con la cronología de Timeo, Licofrón pensaba que los mil años se cumplían en el 331 a.C., fecha que coincide con el triunfo de Gaugamela, con el que Alejandro conquista Persia. White (2000: 129) señala que Licofrón no aclara cuántas jóvenes son porque supone que el público lo sabe; el uso de plural por dual es homérico y helenístico.

41 Hurst (1998: 180) considera que estos hechos son $\dot{\alpha} \mu \alpha \rho \tau i ́ \alpha$ cometida sin maldad. 
misma Casandra es personaje trágico, pues sabe que marcha a su ruina y no puede evitarla, aunque no por elección libre. Los demás no pueden evitarla porque ni siquiera advierten su peligro. La $\pi \varepsilon \rho \iota \varepsilon \dot{\varepsilon} \tau \varepsilon 1 \alpha$, claro está, es la ruina

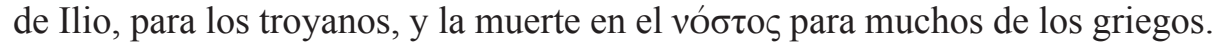

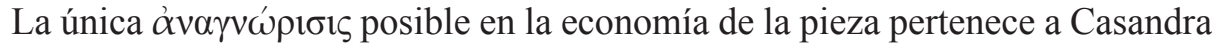
misma, quien por su inspiración profética sí sale de la ignorancia acerca del porvenir, pero el no poder comunicarlo le genera un lamento trágico (vv. 1451 ss.); por otra parte, reiteradamente expresa su dolor personal: por la patria (6972), por la persecución de Héctor (258 ss.), por la muerte de este hermano (302 ss.), por su propia muerte (1108 ss.), por el destino de las muchachas locrias (1141 ss.) y el de su madre Hécaba (1174 ss.) y por la destrucción de la casa de Idomeneo (1214 ss.). Sin embargo, al anunciarse también un culto de honor a Casandra (1126 ss.) y uno a Héctor (1189 ss.) y un futuro de cierta grandeza para los descendientes de los troyanos (ya Alejandro Magno, ya los romanos), la 'situación trágica' de los personajes, sin perder dolor ni patetismo, presenta una 'luz' de resarcimiento y felicidad futuros, si no para ellos, al menos para su posteridad.

Sí parece evidente la búsqueda del patetismo, rasgo esencial de la tragedia desde la más antigua pieza conservada, Persas de Ésquilo, en la que los lamentos de los medos y la figura desgarrada de Jerjes conmueven más allá de la condición de enemigos. Baste como ejemplo la descripción del asesinato de la misma Alejandra en manos de Clitemnestra (1108-1119). Asimismo, es obvio que el lenguaje, si puede 'pecar' de oscuro, no lo hace de coloquial: la lengua tiene la 'altura' propia de la tragedia; y además, el asunto transmite una tensión de sentimientos y pensamientos también típica de la tragedia: el dolor por una ruina que no puede ser evitada y cuya revelación no es creída por nadie. El tratamiento está estilizado, sin el 'realismo' más apropiado a la comedia y sin preocupación por la verosimilitud.

Además del problema de si Alejandra es o no una tragedia, se planteó la posibilidad de su representación. Mascialino la niega; West la ve probable, aunque la imagina monótona y aburrida ${ }^{42}$. Nosotros la comparamos, por ejemplo, con el largo segundo episodio de Siete contra Tebas, donde los siete parlamentos dobles del mensajero y de Eteocles pueden parecer aburridos, pero el contenido lo impide: los escudos no aparecen en escena, pero su descripción

42 Cf. West (1984: 145). 
y su interpretación bastan para generar expectativa y creciente 'tragicidad'.

En escena han de estar un actor que representa al Guardia-servidormensajero y al menos otro, silente, que representa a Príamo, aunque podría haber algunos más que pertenecieran a la corte, también actores mudos (recordemos que en Euménides de Ésquilo son actores mudos los jurados y quizás lo fueran los consejeros persas en Fenicias de Frínico ${ }^{43}$ ). Es posible, por otra parte, que la profecía misma estuviera en boca de otro actor, a modo de 'visualización' de las palabras de Casandra: este actor vestido de mujer podría, además, con ademanes, movimientos y recursos propios de la oratoria, 'representar' o 'mimar' muchos de los hechos aludidos. Hoy, un efecto de luces pondría en primer plano a Casandra y dejaría en penumbras al Mensajero. Bien observa Martina que los relatos de mensajeros son palabras que 'crean espacios'; aunque no haya sangre, su evocación puede resultar más dramática, porque interesa lo interior y espiritual; la palabra crea escena, enciende la imaginación, de modo que el texto mismo produce un efecto trágico independientemente de la representación ${ }^{44}$. Y en Alejandra son evocados muchos espacios, muchas batallas y muchas adversidades.

No hay indicio de coro ni de música de acompañamiento. Esto no extraña en el teatro helenístico, pues ya desde el postclásico el coro estaba en decadencia ${ }^{45}$. En cuanto a 'partes' de la obra, está clara la división en prólogo, episodio (con tres unidades temáticas ${ }^{46}$ ) y epílogo, sin pretender que haya epeisódia y stásima como en el teatro del s. v.

Pensamos que la pieza pudo ser representada, pero no en el ámbito y ocasión clásicos de las Grandes Dionisias, sino en el salón del Museo de Alejandría: así como es diferente la concepción del género, también lo es su representación, menos general, para un público más reducido y más erudito. En la actualidad, en que es frecuente asistir a presentaciones de stand up y

43 Cf. Lloyd Jones (1966: 23).

44 Cf. Martina (1993: 134-8).

45 Cf. por ejemplo Sifakis (1963), TAPLIN (1976).

46 Caída de Troya (vv. 31-364); nóstoi, desventuras de los griegos en el viaje de regreso (vv. 365-1089 = "Odisea licofroniana"); miserias de los griegos en su retorno de Troya (vv. 1090-1450). Sobre el nóstos central, cf. Gigante Lanzara (1997), SCHADE (1999). 
de monólogos, quizás resulte menos extraño aceptar la posibilidad de la representación. Pero entonces hay que quitarse de la mente la modalidad del teatro del s. v e imaginar, en cambio, el origen remoto de la tragedia, con un solo agonista o recitador, incluso anterior al diálogo entre ú Y esta forma 'arcaica' de la tragedia estaría en consonancia con la ambientación y el asunto mismos de Alejandra, una profecía de desgracias emitida en tiempos micénicos.

Pero es importante destacar, por último, que la estructura de esta obra puede ser antecedente de piezas bizantinas como Amistad exiliada, de Teodoro Pródromos; mas de esto nos ocuparemos en otro lugar. 


\section{REFERENCIAS BIBLIOGRÁFICAS}

BrACCESI, L. (1992): “Licofrone e l'interpolatore augusteo", Athenaeum 80, 506-511.

Cavallero, P. (2006): "Trygoidía: la concepción trágica de Nubes de Aristófanes", Emerita 74/1, 89-112.

Ceccarelli, P.-SteinrüCK, M. 1995: “À propos de schol. in Lycophronis Alexandram 1226", $M H$ 52, 77-89.

Cessi, C. (1912): “Lycophronea”, SIFC 19, 73-81.

Clúa Serena, J. (1997): "Notas críticas al texto de la Alejandra de Licofrón”, Emerita 65, 57-63.

Clúa Serena, J. (2003): "Poética e innovación en la Alejandra de Licofrón: $\tau$ ì

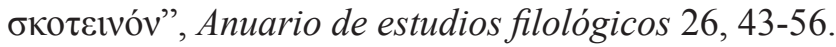

Corssen, P. (1913): "Ist die Alexandra dem tragiker Lykophron absusprechen?", RhM 68, 321-335.

Crisculolo, U. (1970): "Per la tradizione papiracea dell'Alexandra di Licofrone", Dioniso 44, 72-78.

Cusset, Ch.- Kolde, A. (2013): "The rhetoric of the riddle in the Alexandra of Lycophron", en J. Kwapisz et alii edd. The muse at play; riddles and wordplay in Greek and Latin poetry, Berlin-Boston, 167-183.

Cf. http://www.hisoma.mom.fr/sites/hisoma.mom.fr/files/Cusset_Kolde.pdf

Del Ponte, A. (1981): "Lycophronis Alexandra: la versificazione e il mezzo espressivo", SIFC 53, 101-133.

GefFCKen, J. (1891): “Zwei Dramen des Lycophron”, Hermes 26, 33-42.

GeFFCKen, J. (1891b): “Zur Kenntniss Lykophrons”, Hermes 26, 567-579.

Giangrande, C. (1967): “Arte allusiva and Alexandrian epic poetry”, CQ 17, 85-97.

Gigante Lanzara, V. (1997): "Il vó $\tau \tau$ o̧ di Odisseo e la prospezione della memoria. Lycophr. Alex. 648-819”, Maia 49, 43-68.

Gigante Lanzara, V. (1999): "Echi dell'Alessandra nella poesia latina", Maia 51, 331-347.

GRIFFITHS, J. (1986): "Lycophron on Io and Isis", The Classical Quarterly 36/2, 472-477.

Hartmann, A. (1929): "Ein Münchener Lykophron-Papyrus”, Philologus 81, 228-233.

HaumesSER, L. (2014): "Les temps de la prophétie: Lycophron et le décor de la tombe François", Aitia [En ligne] 4, mis en ligne le 19 janvier 2015, consulté le 28 juillet 2015. URL: http://aitia.revues.org/1058 
Holzinger, C. von (1895): Lykophron's Alexandra, Leipzig.

Hurst, A. (1998): "Lycophron: la condensation du sens, le comique et l'Alexandra", en M. Trédé- Ph. Hoffmann, Le rire des anciens, Paris, École Normale Supérieure, 177-187.

KöRTE, A.- HäNDEL, P. (1973): La poesía helenística, Barcelona, Labor. LAMBIN, G. (2005): L'Alexandra de Lycophron, étude et traduction, Rennes. https://hal.inria.fr/file/index/docid/372659/filename/article.pdf LivreA, E. (1989): “P. Oxy. 2463: Lycophron and Callimachus”, CQ 39, 141147.

Marandino, A. (2010): Scrivere e leggere l'Alessandra di Licofrone: sulle tracce dei papiri. Tesis doctoral. Roma, Università Tor Vergata.

https://art.torvergata.it/retrieve/handle/2108/1321/6551/Tesis.pdf

Martina, A. (1993): "La Poetica di Aristotele e l'Edipo re di Sofocle: $\alpha \mu \alpha \rho \tau i ́ \alpha$

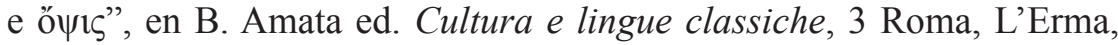
87-138.

Mascialino, L. (1956): ed. Licofrón, Alejandra, texto revisado y traducido por L. M., Barcelona, Alma Mater.

Momigliano, A. (1927-8): "Note sull' Alessandra di Licofrone", Bollettino di filologia classica 34, 250-255.

Momigliano, A. (1942): “Terra marique”, Journal of Roman Studies 32, 53-64. NAfissi, M. (1997): "Riso fatale. Herakles e Kalchas a Herakleia Lucana (Lyc., Alex. 979-81; schol vet. 978; 980)", PP 52, 32-60.

Niebuhr, B. (1827): “Über das Zeitalter Lycophrons des Dunkeln”, RhM 1, $108-117$.

Perret, J. (1942): Les origines de la légende troyenne de Rome, Paris.

Prioux, E. (2009): "Lycophron et les errances d'Enée", Eruditio antiqua 1, 105-122.

Rollo, W. (1928): “Quo tempore Lycophron Alexandram composuerit?”, Mnemosyne 56/1, 93-101.

Rossi, L. (1971): "I generi letterari e le loro leggi scritte e non scritte nelle letterature classiche", BICS 18, 69-94.

Rostropowicz, J. 1996: "The alexandrians and the drama (several remarks and reflexions)", Eos 84, 269-275.

Schade, G. (1999): Lycophrons' 'Odyssee’. Alexandra 648-819, Berlin, De Gruyter.

Scheer, E. (1879): "Die Ueberlifierung der Alexandra des Lykophron", RhM $34,272-291$ y $442-473$. 
SCHEeR, E. 1908 (1881): ed. Lycophronis Alexandra recensuit E. Scheer, Berolini, Weidmann.

SIFAKIS, G. (1963): "High state and chorus in the Hellenistic theatre", BICS 10, 31-45.

Spatafora, G. (1995): "Licofrone, Alessandra 1356", AC 64, 195-6.

SudHAus, S. (1908): "Die Abfassungszeit der Alexandra", RhM 63, 481-487.

TAPLIN, O. (1976): "XOPOY and the structure of postclassical tragedy", $L C M$ $1,47-50$.

TARN, W. (21927): Hellenistic civilisation, London.

WEST, S. (1983): "Notes on the text of Lycophron", CQ 33, 114-135.

WEST, S. (1984): "Lycophron italicised", JHS 104, 127-151.

White, H. (1997): "An interpretative problem in Lycophron's Alexandra", Habis 28, 49-51.

White, H. (2000): “Textual problems in Lycophron”, QUCC 66, 125-131. 